Check for updates

Cite this: RSC Adv., 2017, 7, 31567

\title{
High wet-strength, thermally stable and transparent TEMPO-oxidized cellulose nanofibril film via cross-linking with poly-amide epichlorohydrin resin
}

\author{
Weisheng Yang, (DD ab Huiyang Bian, ${ }^{a}$ Liang Jiao, ${ }^{a}$ Weibing $\mathrm{Wu}^{,}{ }^{\mathrm{a}}$ Yulin Deng ${ }^{\mathrm{b}}$ \\ and Hongqi Dai ${ }^{\star a}$
}

\begin{abstract}
One of the major challenges towards the practical application of nanocellulose films is to maintain their high mechanical properties under humid environment. Herein, the physicochemical properties of TEMPOoxidized cellulose nanofibril (TOCNs) films cross-linked with different dosages of polyamide epichlorohydrin resin (PAE) were investigated. The PAE/TOCNs film containing $0.5 \mathrm{wt} \%$ PAE was treated via an impregnation method in a 0.9 wt\% PAE solution. The resulting film exhibited a high transparency of $79.5 \%$ at a wavelength of $600 \mathrm{~nm}$ with high tensile strength and Young's modulus of approximately $135 \mathrm{MPa}$ and $11 \mathrm{GPa}$, respectively. A high wet strength of $95 \mathrm{MPa}$ was also obtained due to the compact cross-linking net structure. FTIR spectra indicated that the surface carboxyl groups of the TOCNs were converted into an ester bond with the active groups of PAE, which effectively improved the thermostability of the TOCN/PAE hybrid films.
\end{abstract}

Received 4th May 2017

Accepted 28th May 2017

DOI: $10.1039 / \mathrm{c} 7 \mathrm{ra0} 0009 \mathrm{~g}$

rsc.li/rsc-advances mechanical properties of the nanocellulose-based materials. ${ }^{10}$ During the process of extraction of the TOCNs via chemical modification of TEMPO-mediated oxidation, abundant carboxyl groups were position-selectively formed on the TOCN surfaces. $^{11}$ Via the adsorption of cationic surfactants or quaternary alkylammonium salts, a hydrophobic layer was coated on the TOCN surfaces. ${ }^{12,13}$ The wet tensile strength of the TOCN films could be improved via forming covalent or physical cross-linkage between CNFs and polymer matrices, including phenolic resins, epoxy, starch, chitosan, etc., although these composite materials need multiple and time-consuming procedures for their preparations. ${ }^{\mathbf{1 4 - 1 8}}$

Polyamine epichlorohydrin resin (PAE), as a water-soluble thermosetting polymer, has abundant active groups including azetidinium and alkyl functional groups ${ }^{19}$ and is commonly added to paper products to improve their wet strength. Previously, PAE cross-linked TOCN aerogels and films with excellent performances have been prepared..$^{\mathbf{2 0 2 1}}$ The TOCNs with abundant anionic carboxyl groups have a high adsorbing capacity for PAE. ${ }^{19}$ Therefore, large dosages of PAE will cause aggregation of the TOCNs. This instability leads to an uneven distribution of PAE and TOCNs within the composites. Herein, a two-step process was used. First, the PAE/TOCN films with low concentrations of PAE were produced via the solution-casting method; these films showed high wet stability caused by the crosslinking between TOCNs and the PAE cross-linker. Then, these films were soaked in PAE aqueous solution. During the impregnation process, the PAE cross-linker is allowed to diffuse ajiangsu Co-Innovation Center for Efficient Processing and Utilization of Forest Resources, Nanjing Forestry University, Nanjing, Jiangsu, 210037, China. E-mail: hgdhq@njfu.edu.cn; Tel: +86-25-85428932

${ }^{b}$ School of Chemical \& Biomolecular Engineering and Renewable Bioproducts Institute, Georgia Institute of Technology, 500 10th Street N.W., Atlanta, GA 30332, USA 
into the TOCN films. This allows the addition of very high PAE content within the final hybrid films, avoiding an uneven distribution. The cross-linking reactions were induced via a simple heating process. The entire process is green, safe, environmentally friendly, and does not involve complex chemical reactions and toxic organic solvents.

Herein, the high-wet-strength and thermal-stable TOCN films were prepared, and their structure, hydrophobicity, mechanical properties, and thermostability were studied. The mechanism of water resistance and thermostability enhancement that results from the cross-linking between TOCNs and PAE was also illustrated.

\section{Experimental}

\section{Materials}

Aqueous 0.5 wt $\%$ TOCN suspensions were prepared using TEMPO-mediated oxidation as described in our previous study. ${ }^{22}$ A cationic papermaking-grade polyamide epichlorohydrin resin (PAE) solution (Tianma Specialty Chemicals Co., China) was used without any purification.

\section{Fabrication of the PAE/TOCN hybrid films}

The entire preparation process is shown in Scheme 1 . The 0.5 wt $\%$ aqueous TOCN suspension and 0.1 wt $\%$ PAE dispersion were mixed under an ice bath under an ultrasonic condition at $300 \mathrm{~W}$ output power (X0-650, xianou Instruments Ltd., China). The dosages of PAE were $0.1 \mathrm{wt} \%, 0.3 \mathrm{wt} \%$, and $0.5 \mathrm{wt} \%$ based on the oven-dry TOCN weight. The solution-casting method was performed by pouring the mixture slurry into polystyrene Petri dishes (diameter $60 \mathrm{~mm}$ ) and drying at room temperature for few days. After drying, the dried hybrid films were heated at $105{ }^{\circ} \mathrm{C}$ for $30 \mathrm{~min}$ to induce crosslinking. All the samples were conditioned at $23{ }^{\circ} \mathrm{C}$ and $50 \%$ RH for $24 \mathrm{~h}$ before measurements.

Then, the PAE/TOCN films containing 0.5 wt $\%$ PAE were soaked in $0.1 \mathrm{wt} \%, 0.5 \mathrm{wt} \%$, and $0.9 \mathrm{wt} \%$ PAE slurries for $2 \mathrm{~h}$. Subsequently, the wet films were dried at room temperature for few days. After drying, the films were heated at $105^{\circ} \mathrm{C}$ for $30 \mathrm{~min}$

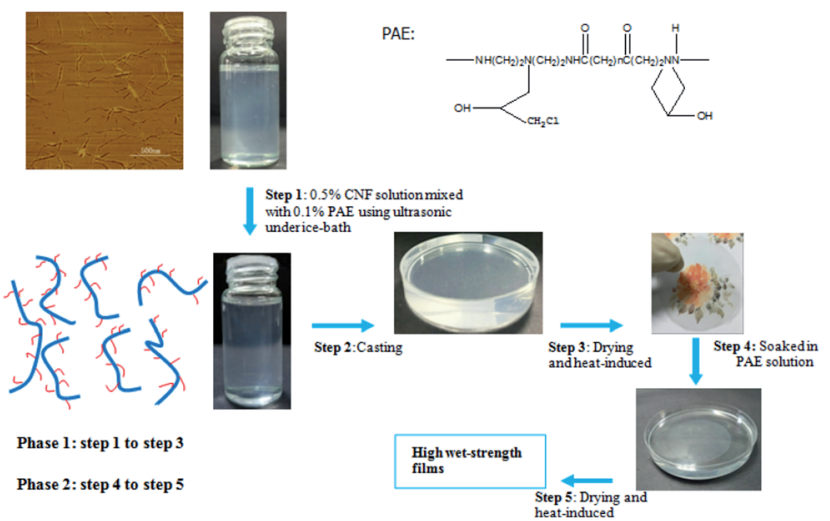

Scheme 1 A schematic of the experiments for the preparation of TOCN/PAE hybrid films. to induce crosslinking. All the films were conditioned at $23{ }^{\circ} \mathrm{C}$ and $50 \% \mathrm{RH}$ for $24 \mathrm{~h}$ before measurements.

\section{Analyses}

FE-SEM (JSM-7600F, JEOL Ltd., Japan) was carried out to characterize the cross-section of the fracture surface of the films. The thicknesses of films were calculated using a micrometer caliper. The packing densities of the samples were calculated from the dimension and weight of the hybrid films after conditioning at $23{ }^{\circ} \mathrm{C}$ and $50 \% \mathrm{RH}$. According to the weights obtained before and after heating at $105{ }^{\circ} \mathrm{C}$ for $4 \mathrm{~h}$, the moisture contents of the conditioned films could be calculated. The optical properties of the hybrid films were studied using a UVvis spectrophotometer (Lambda 950, PerkinElmer, USA) in the wavelength range from 200 to $1100 \mathrm{~nm}$ with a scan speed of $2 \mathrm{~nm} \mathrm{~s}^{-1}$. The light transmittance of the TOCN/PAE mixture casting solutions was also tested using the same method in the wavelength range from 300 to $800 \mathrm{~nm}$. Fourier transform infrared (FTIR) spectra of the hybrid films were obtained using an FTIR spectrometer (VERTEX 80V, Bruker, Germany) at room temperature. The zeta potential of the TOCN/PAE mixture suspensions at $0.5 \mathrm{wt} \%$ was characterized using a Zeta potential analyzer (Zetasizer Nano ZS, Malvern Instruments Ltd., UK) at ambient temperature. The surface water resistance of the hybrid films was measured using a dynamic CA analyzer (FTA200) at room temperature, and three measurements were conducted for each sample. Mechanical tests of dry hybrid films were carried out using a tensile tester (H25KT, Tinius Olsen, USA) with a $500 \mathrm{~N}$ load cell at $1 \mathrm{~mm} \mathrm{~min}^{-1}$ at room temperature. Before the test, all the samples were conditioned at $23{ }^{\circ} \mathrm{C}$ and $50 \% \mathrm{RH}$ for at least $24 \mathrm{~h}$. The film specimens had widths and lengths of $3 \mathrm{~mm}$ and $50 \mathrm{~mm}$, respectively. The hybrid films were soaked in fresh water for $2 \mathrm{~h}$, and excess water was removed using a blotting paper. The water content of the wet films was calculated from the change in weight of the films. According to TAPPI 456 OM-87, the wet mechanical properties were measured using a tensile tester (H25KT, Tinius Olsen, USA). The micrometer reading was carried out for calculating the thickness of the wet film. The thermal stability of the hybrid films was measured via thermogravimetric (TG) analysis using a thermogravimetric analyzer TGA (Q5000IR, TA instruments, USA). About $5 \mathrm{mg}$ freeze-dried samples were weighed in a platinum pan and heated from 35 to $600{ }^{\circ} \mathrm{C}$ at a heating rate of $10{ }^{\circ} \mathrm{C}$ $\mathrm{min}^{-1}$ under a high-purity nitrogen flow of $40 \mathrm{~mL} \mathrm{~min}^{-1}$.

\section{Results and discussion}

\section{Dispersity of the PAE/TOCN mixture suspensions}

The zeta potential values and light transmittance of the TOCN/ PAE suspensions are listed in Table 1. TOCNs can be dispersed in water to form very stable transparent aqueous solutions with the help of strong repulsion forces between the negative charges on the nanofiber surfaces. The zeta potential values reflect the surface charge state and the stability of the disperse system. ${ }^{23}$ According to Table 1, the zeta potential value constantly reduced from $52.50 \mathrm{mV}$ to $44.15 \mathrm{mV}$ with increasing PAE 
Table 1 Light transmittance and zeta potential values of the TOCN/ PAE suspensions

\begin{tabular}{llll}
\hline Sample & $\begin{array}{l}\text { PAE content } \\
(\%)\end{array}$ & $\begin{array}{l}\text { Zeta potential } \\
(-\mathrm{mV})\end{array}$ & $\begin{array}{l}\text { Transmittance }^{a} \\
(\%)\end{array}$ \\
\hline $\mathrm{A}$ & 0 & 52.5 & 88.1 \\
$\mathrm{~B}$ & 0.1 & 48.3 & 85.8 \\
$\mathrm{C}$ & 0.3 & 46.5 & 85.5 \\
$\mathrm{D}$ & 0.5 & 44.2 & 85.4 \\
\multicolumn{4}{l}{ Transmittance at $600 \mathrm{~nm}$ wavelength. }
\end{tabular}

content from 0 to $0.5 \mathrm{wt} \%$. It is probably because TOCNs carry a stronger negative charge on their surface and have a stronger affinity for cationic PAE. As shown in the inset in Fig. 1, TOCN suspensions with slight addition of cationic PAE presented excellent light transmittance. To further evidence the transparency of the TOCN/PAE suspensions, the transmittance spectra of diluted suspensions in the range of $200-1100 \mathrm{~nm}$ were obtained using a UV instrument. A slight decrease in the transmittance was observed after adding cationic PAE; however, the TOCN/PAE suspensions still exhibited a high transparency of approximately $85 \%$ at a wavelength of $600 \mathrm{~nm}$.

\section{Structure of the TOCN/PAE hybrid films}

As shown in Scheme 2, TOCN films with a compact structure were formed via the bonding of interfibrillar hydrogen. Under humid conditions, these films exhibited poor mechanical properties because water molecules were adsorbed on the TOCN surface and acted as a competitive agent for interfibrillar hydrogen bonding. In phase 1, TOCN/PAE films had great wet stability. However, within these films, a cross-linked network could not be formed because of the slight addition of PAE, and the resultant wet strength for these films was too weak to be measured. In phase 2 , the formation of the water-insoluble

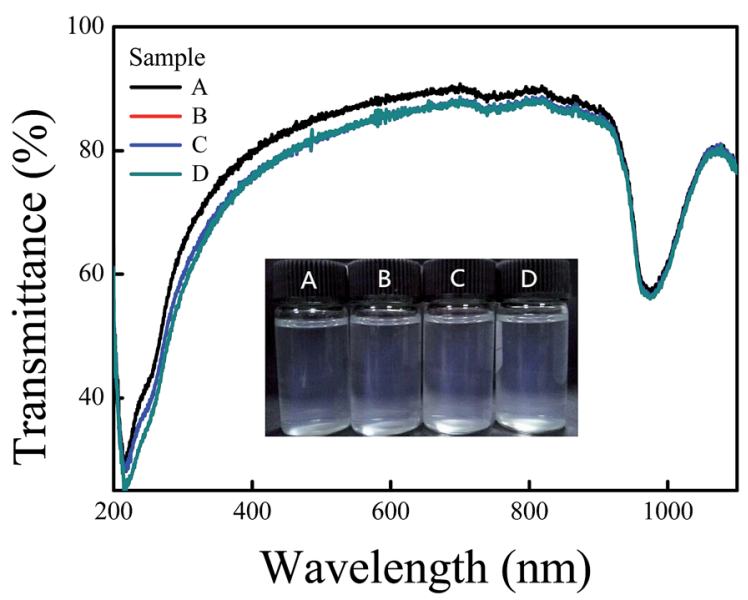

Fig. 1 Light transmittance spectra of the TOCN/PAE suspensions with various PAE dosages $(0,0.1,0.3$, and 0.5 wt $\%$ based on dry TOCN weight), denoted as sample $A, B, C$, and $D$, respectively. The inset shows the images of the TOCN/PAE suspensions.

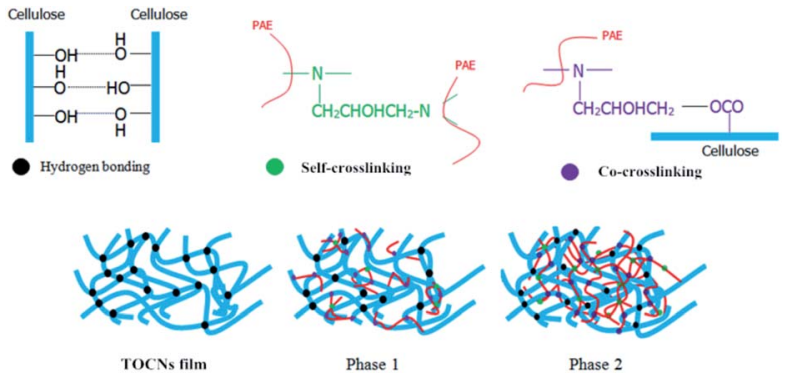

Scheme 2 Sketch illustrating the interfibrillar hydrogen bonding in TOCN films and the cross-linking structure of the TOCN/PAE films for phases 1 and 2. The black, green, and purple dots represent hydrogen bonding, self-crosslinking of PAE, and co-crosslinking between PAE and TOCNs, respectively.

network effectively limited the water absorption and protected interfibrillar hydrogen bonding, endowing the TOCN/PAE films with high wet strength.

The fundamental properties of the hybrid films are shown in Table 2 . The density values showed an increasing tendency with the increasing PAE content, which was the result of the compact cross-linking structure within the hybrid films. The highest moisture content of $10.2 \%$ was found for the TOCN films (sample 1), and the other films (sample 2-7) had relatively low moisture contents that ranged from $7.3 \%$ to $7.8 \%$. The result indicated that the cross-linking of the TOCN films with PAE possessed great water resistance.

To analyze the nanostructure of the hybrid films, the fracture surfaces were characterized via FE-SEM. The lamellar structure can be obviously observed in Fig. 2(a)-(c). Compared to the neat TOCN films (sample 1), TOCN/PAE hybrid films (sample 4, 7) had denser packed layers. Fig. 2(d) shows the light transmittance of the hybrid films with a thickness of approximately $35 \mu \mathrm{m}$. All films had high optical transmittance of $70-90 \%$ at a wavelength of $600 \mathrm{~nm}$ (Table 2). A trend was suggested, where the hybrid films had decreasing transparency with the increasing PAE content. This is probably because of the UV absorption of PAE and the yellowing phenomenon during the heat-induced cross-linking process. ${ }^{24,25}$

To ascertain the cross-linking between TOCNs and PAE cross-linker, FTIR analysis was performed to analyze the changes in the chemical structure, and the spectra are shown in Fig. 2(e). The adsorption bands observed in the region of 3650$3000 \mathrm{~cm}^{-1}$ and $2900 \mathrm{~cm}^{-1}$ were related to $\mathrm{O}-\mathrm{H}$ stretching vibration and $\mathrm{C}-\mathrm{H}$ stretching vibrations, respectively. ${ }^{\mathbf{2 6}}$ The peaks at 1429,1110 , and $896 \mathrm{~cm}^{-1}$ indicated the typical structure of cellulose found in all samples, which revealed that there were no significant structural changes after the cross-linking reaction. ${ }^{27}$ As the PAE content increased, a peak was observed around $1633 \mathrm{~cm}^{-1}$, corresponding to the amide group belonging to PAE. ${ }^{19}$ Compared to the neat TOCN film, a new band was observed around $1718 \mathrm{~cm}^{-1}$, which was assigned to the $\mathrm{C}=\mathrm{O}$ vibrations from the ester functions in the crosslinking network. ${ }^{\mathbf{2 0} 28}$ The existence of ester functions in the 
Table 2 Fundamental properties of the TOCN/PAE hybrid films

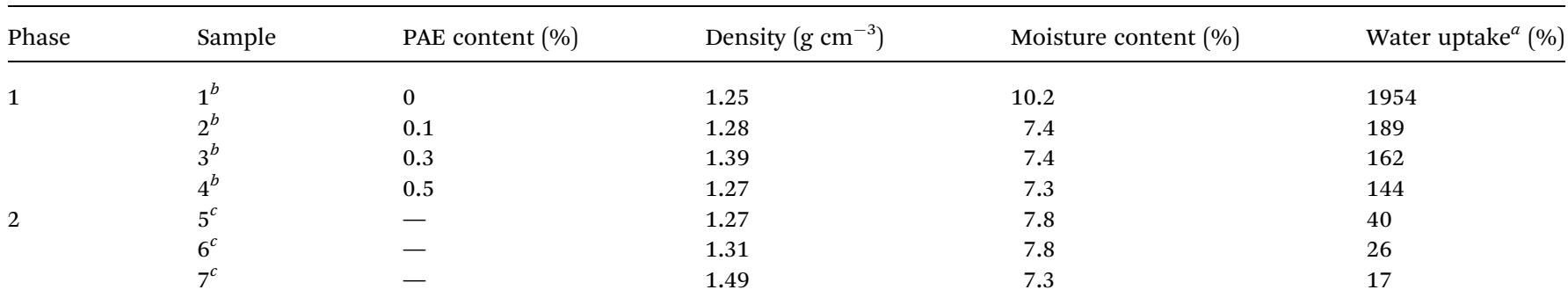

${ }^{a}$ Measured after soaking the films in water for 2 h. ${ }^{b}$ TOCN/PAE hybrid films were prepared via solution casting, with the PAE content of $0 \%, 0.1 \%$, $0.3 \%$, and $0.5 \%$, and the samples were denoted $1,2,3$, and 4 , respectively. ${ }^{c}$ TOCN/PAE hybrid films were produced by a impregnation treatment of sample 4 with $0.1 \mathrm{wt} \%, 0.5 \mathrm{wt} \%$, and $0.9 \mathrm{wt} \%$ PAE slurry, respectively, and the samples were denoted 5,6 , and 7 .
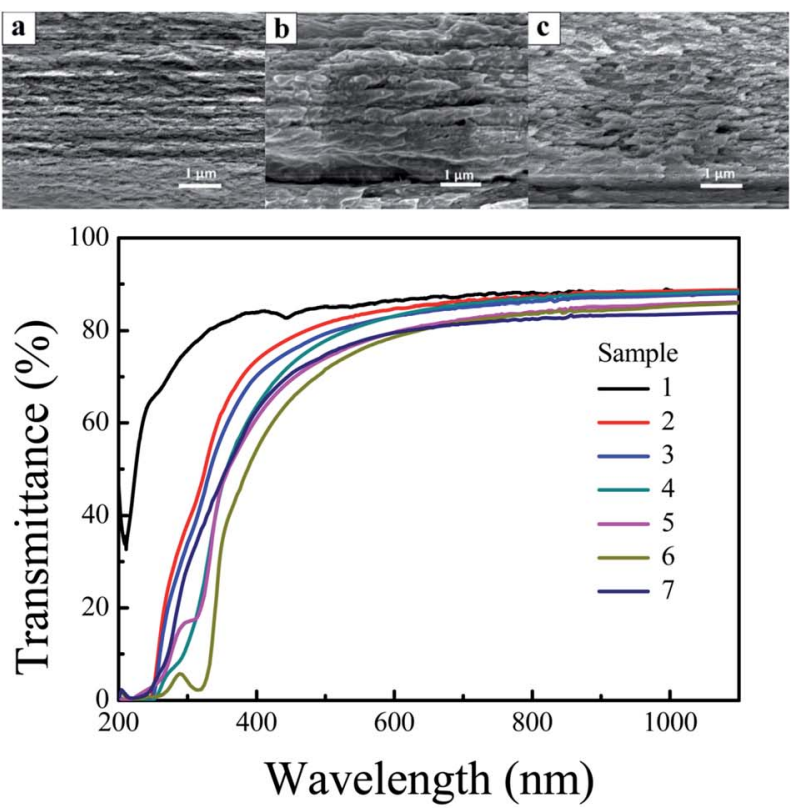

(d)

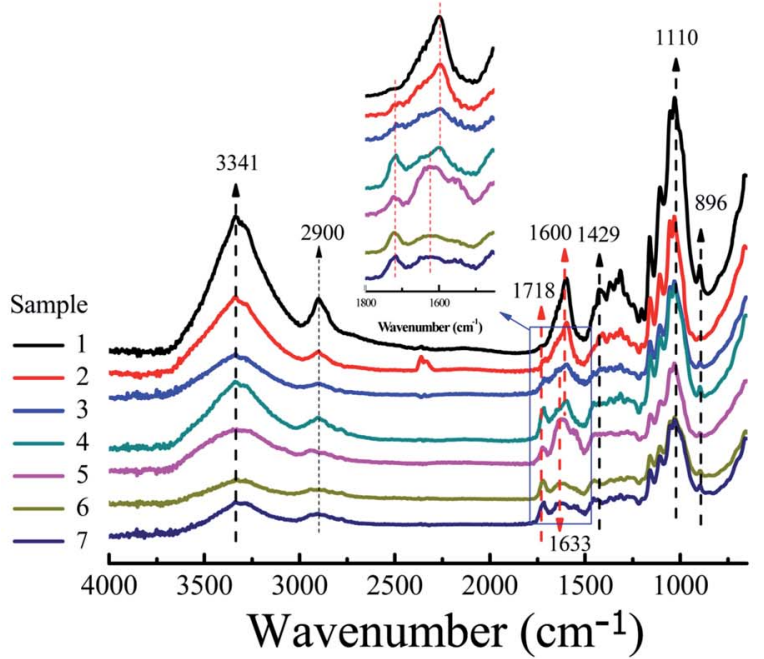

(e)

Fig. 2 (a-c) Fracture surfaces of the sample 1, 4, and 7 films. ( $d$ and e) Light transmittance spectra and FTIR spectra of the TOCN/PAE hybrid films. hybrid films strongly proved the covalent bond linkage between PAE and TOCNs after thermal initiation.

\section{Tensile strength of the TOCN/PAE hybrid films}

The mechanical properties of the dried TOCN/PAE films are shown in Table 3. All the film samples had high Young's modulus of 9.0-11.2 GPa, high tensile strength of 102-135 MPa, and strain-to-failure values of $1.1-1.4 \%$. Herein, the tensile strength of $112 \mathrm{MPa}$ for the neat TOCN films was lower than the previously reported values $(225 \mathrm{MPa}){ }_{,}^{29}$ which was attributed to the lower density of the resulting films. In phase 1 , the tensile strength slightly decreased as the PAE content increased from $0 \%$ to $0.5 \%$. In fact, the changes were not obvious because only a very small amount of PAE was added. In phase 2, an impregnation method with the PAE dispersion was used to treat the films. The obtained hybrid films showed higher mechanical performances than the neat TOCN films. The stiffness of these films was improved probably by the formation of TOCN crosslinking with the PAE cross-linker.

The moisture content of the wet hybrid films was measured after soaking in water for $2 \mathrm{~h}$ (Table 2). The highest moisture content of $1954 \%$ was found for the neat TOCN films with a hydrophilic nature. As the amount of PAE increased, the moisture content of the hybrid films dramatically decreased, ranging from $17 \%$ to $189 \%$. The results indicated that the crosslinking structures within the PAE/TOCN hybrid films effectively limited the water absorption and protected the interfibrillar hydrogen bonding. Wet TOCN/PAE hybrid films with high water

Table 3 Tensile properties of the dry TOCN/PAE hybrid films

\begin{tabular}{llll}
\hline Sample & $\begin{array}{l}\text { Tensile strength } \\
(\mathrm{MPa})\end{array}$ & $\begin{array}{l}\text { Young's } \\
\text { modulus (GPa) }\end{array}$ & $\begin{array}{l}\text { Strain at } \\
\text { break (\%) }\end{array}$ \\
\hline 1 & $112 \pm 10$ & $9.4 \pm 1.0$ & $1.3 \pm 0.3$ \\
2 & $108 \pm 7$ & $9.5 \pm 2.0$ & $1.3 \pm 0.1$ \\
3 & $104 \pm 5$ & $9.0 \pm 2.0$ & $1.3 \pm 0.2$ \\
4 & $113 \pm 8$ & $9.3 \pm 1.0$ & $1.1 \pm 0.1$ \\
5 & $117 \pm 12$ & $10.5 \pm 1.5$ & $1.3 \pm 0.1$ \\
6 & $116 \pm 11$ & $10.4 \pm 1.0$ & $1.1 \pm 0.1$ \\
7 & $135 \pm 9$ & $11 \pm 1.5$ & $1.4 \pm 0.2$
\end{tabular}


content usually had a lower tensile strength and higher strainto-failure. These properties were expected because of plasticization induced by water. ${ }^{30,31}$ Fig. 3 shows the stress-strain curves of the wet TOCN/PAE films (samples 5, 6, and 7), and the characteristic data are listed in Table 4 . The wet neat TOCN films (sample 1) and TOCN/PAE films with low PAE content (samples 2, 3, and 4) could not be subjected to the wet tensile measurement because these films were too weak under the water-swollen state. ${ }^{5}$ After soaking with 0.9 wt $\%$ PAE solution, a high wet strength of $95 \mathrm{MPa}$ was obtained for the hybrid films (sample 7) with the formation of water-insoluble networks. These results are superior to the values of the previous report. $^{21,32}$

\section{Water resistance of the PAE/TOCN hybrid films surface}

Contact angle (CA) measurements were carried out to illustrate the changes in the surface hydrophobic properties of the hybrid films. The results of CA values are shown in Fig. 4. The neat TOCNs films (sample 1) exhibited high hydrophilic nature, and the initial water-contact angle of water measured on the films was only $59.73^{\circ}$. Within $17 \mathrm{~s}$, the CA significantly decreased to $39.51^{\circ}$ with the penetration of water into the films. As the amount of PAE increased, the water contact angle of the films increased from $59.73^{\circ}$ to $75.71^{\circ}$, which was the result of the aliphatic chain of PAE. Owing to the formation of the waterinsoluble network, the contact angle values became more stable within the recording time (17 s). The cross-linking between PAE and TOCNs decreased the porosity and limited the water absorption, thus improving the hydrophobicity of the hybrid films.

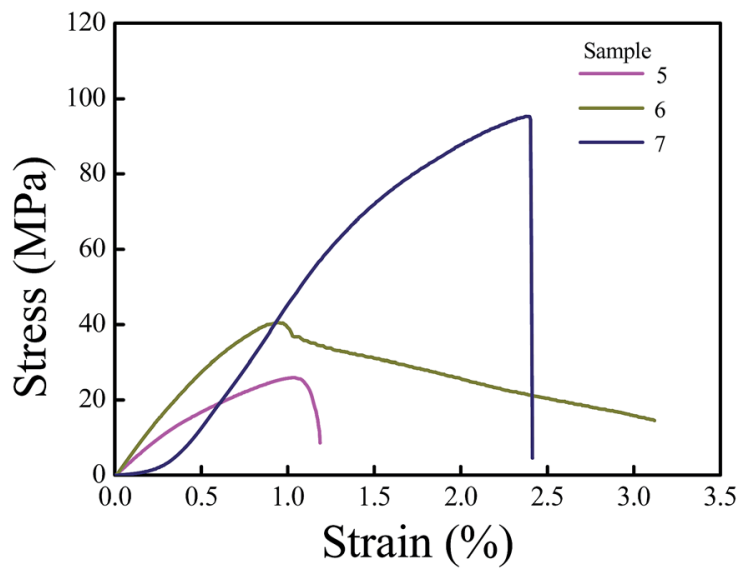

Fig. 3 The stress-strain curves of the wet films (samples 5, 6, and 7).

Table 4 Tensile properties of the wet films (samples 5, 6, and 7)

\begin{tabular}{llll}
\hline Sample & $\begin{array}{l}\text { Tensile strength } \\
(\mathrm{MPa})\end{array}$ & $\begin{array}{l}\text { Young's } \\
\text { modulus }(\mathrm{GPa})\end{array}$ & $\begin{array}{l}\text { Strain at break } \\
(\%)\end{array}$ \\
\hline 5 & $26 \pm 2$ & $3.8 \pm 0.1$ & $1.3 \pm 0.2$ \\
6 & $41 \pm 3$ & $6.1 \pm 0.2$ & $3.1 \pm 0.5$ \\
7 & $95 \pm 5$ & $6.3 \pm 0.2$ & $2.4 \pm 0.4$
\end{tabular}

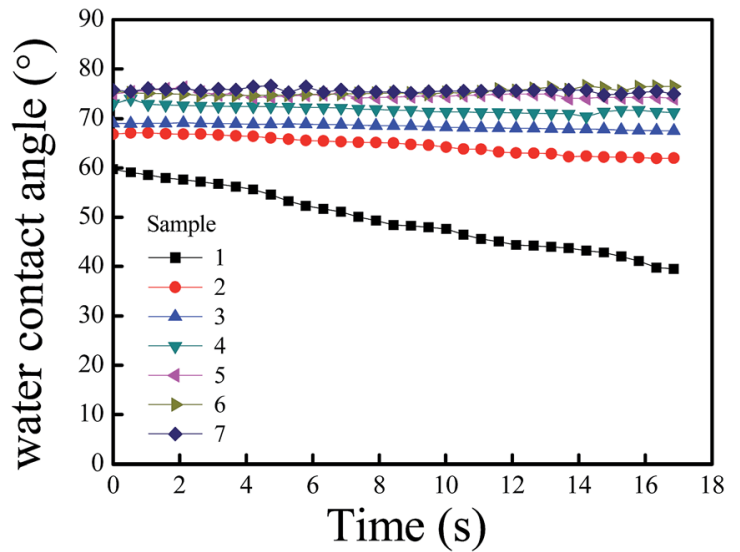

Fig. 4 Water contact angle of the PAE/TOCN hybrid films.

\section{Thermal stability of the PAE/TOCN hybrid films}

The regular wood fibers have thermal stability degradation at around $300{ }^{\circ} \mathrm{C},{ }^{33}$ whereas for TOCNs, degradation begins at 200-220 ${ }^{\circ} \mathrm{C}^{34}$ It is known that the existence of carboxyl groups on the surface of TOCNs causes this decrease in thermal

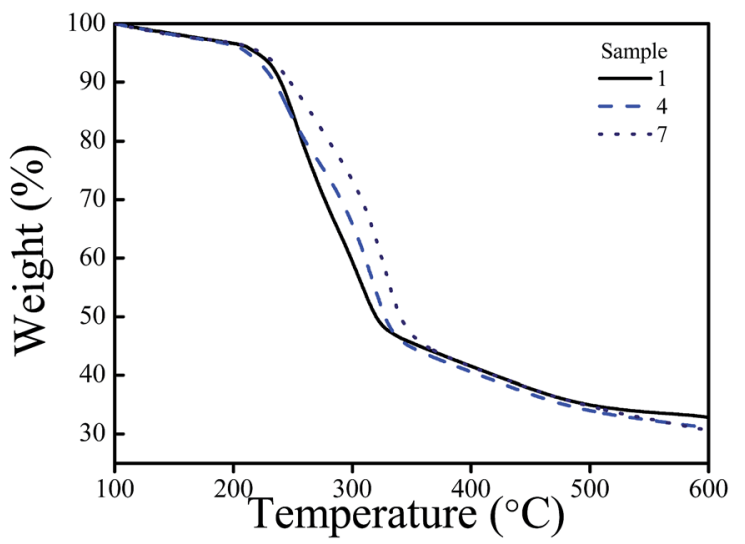

(a)

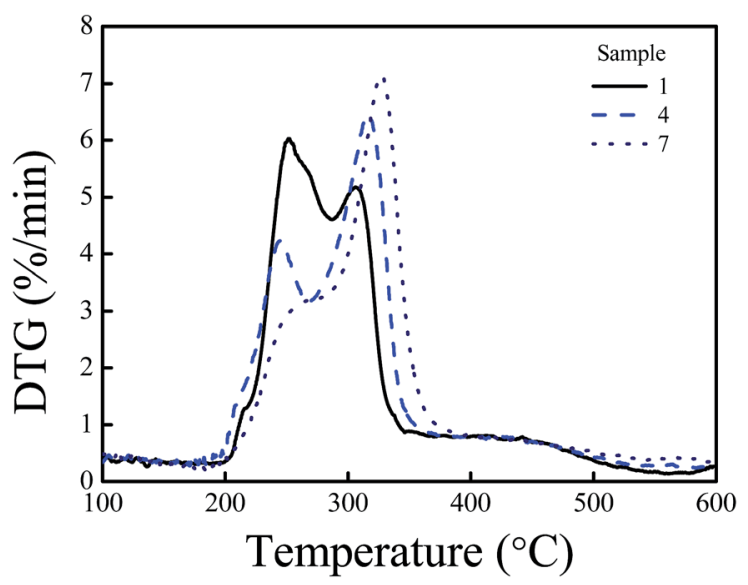

(b)

Fig. 5 (a) TGA and (b) DTG curves of PAE/TOCN hybrid films (samples 1,4 , and 7). 
Table 5 TGA and DTG data of the TOCN/PAE films (samples 1, 4, and 7), measured at a heating rate of $10^{\circ} \mathrm{C} \mathrm{min}-1$

\begin{tabular}{|c|c|c|c|c|c|c|c|}
\hline & & $T_{10 \%}{ }^{a}\left({ }^{\circ} \mathrm{C}\right)$ & \multicolumn{2}{|l|}{ Stage I } & \multicolumn{2}{|l|}{ Stage II } & CY (\%) \\
\hline 4 & 182 & 234 & 245 & 4.2 & 316 & 6.5 & 31.1 \\
\hline 7 & 189 & 248 & 276 & 3.2 & 327 & 7.2 & 30.6 \\
\hline
\end{tabular}

stability. ${ }^{1}$ The TG and the corresponding DTG curves of the films samples are shown in Fig. 5. The slight weight loss caused by the evaporation of absorbed moisture within 30 and $100{ }^{\circ} \mathrm{C}$ was not taken into account for better comparison of the thermal stability of the samples. Moreover, the characteristic data for the TG and DTG curves are given in Table 5. As a result of carboxyl groups being converted into ester bonds, the thermal stability of the TOCN films was slightly improved. For the neat TOCN films (sample 1), the $10 \%$ weight loss occurred at about $239{ }^{\circ} \mathrm{C}$. Owing to the water-insoluble polymer network structure, the $T_{10 \%}$ values of sample 7 films were improved to $248{ }^{\circ} \mathrm{C}$. The $T_{10 \%}$ values of sample 4 films were similar to those of the neat films, indicating the existence of unprotected carboxyl groups within the hybrid films for which similar results were observed via FTIR analysis. As shown in Table 5, char yield (CY) obviously decreased with the improvement of weight ratios of PAE in the films, from 32.8 to $30.6 \%$, which was the result of the decrease in the proportion of TOCNs in the hybrid films.

During the whole heating process, two obvious decomposition behaviors were observed (Fig. 5(b)). It likely represents the decomposition of the carboxyl groups and cellulose molecules. $^{35}$ For the neat TOCN films (sample 1), the Stage I $T_{\max }$ occurred at $252{ }^{\circ} \mathrm{C}$ with a maximum weight loss rate (WLR) of $6.03 \% \mathrm{~min}^{-1}$ and the corresponding data of Stage II were $306{ }^{\circ} \mathrm{C}$ and $5.18 \% \mathrm{~min}^{-1}$. While for the sample 7 films, the Stage I $T_{\max }$ appeared at $276{ }^{\circ} \mathrm{C}$ with a maximum weight loss rate (WLR) of $3.23 \% \mathrm{~min}^{-1}$ and the corresponding data of Stage II were $327^{\circ} \mathrm{C}$ and $7.15 \% \min ^{-1}$.

\section{Conclusion}

In this study, the PAE/TOCN hybrid films were prepared by the covalent bond linkage between TOCNs and PAE. The waterinsoluble net structure limits the water swelling of the films and protects the interfibrillar hydrogen bonding. Under humid conditions, the hybrid films exhibit high mechanical performances. Moreover, the surface carboxyl groups of the TOCNs were converted into ester bonds with the azetidinium groups of PAE. This change is beneficial to improve the thermostability of the TOCN films. As a result, modified TOCNs films had a reduced moisture uptake and higher surface water contact angle and wet tensile properties as compared to the neat TOCN films. In addition to the expected improvement of wet strength, the enhancement of thermostability and dry tensile strength were also observed. The results observed in this study will improve the applications of TOCN-based films under high humid conditions.

\section{Acknowledgements}

Weisheng Yang thanks the support received from the Introduction of Advanced International Project of Forestry Science and Technology (Grant Number: 2015454), the National Natural Science Foundation of China (Grant Number: 31470599), and the Priority Academic Program Development of Jiangsu Higher Education Institutions (PAPD).

\section{References}

1 H. Fukuzumi, T. Saito and T. Iwata, Biomacromolecules, 2009, 10, 162-165.

2 Y. Okahisa, A. Yoshida, S. Miyaguchi and H. Yano, Compos. Sci. Technol., 2009, 69, 1958-1961.

3 D. Klemm, F. Kramer, S. Moritz, T. Lindström, M. Ankerfors, D. Gray and A. Dorris, Angew. Chem., Int. Ed., 2011, 50, 54385466.

4 K. Syverud and P. Stenius, Cellulose, 2009, 16, 75-85.

5 A. J. Benítez, J. Torresrendon, M. Poutanen and A. Walther, Biomacromolecules, 2013, 14, 4497-4506.

6 J. H. Kim, B. S. Shim and H. S. Kim, International Journal of Precision Engineering and Manufacturing-Green Technology, 2015, 2, 197-213.

7 C. Goussé, H. Chanzy, G. Excoffier, L. Soubeyrand and E. Fleury, Polymer, 2002, 43, 2645-2651.

8 G. Rodionova, M. Lenes, Ø. Eriksen and $\emptyset$. Gregersen, Cellulose, 2011, 18, 127-134.

9 R. K. Johnson, A. Zink-Sharp and W. G. Glasser, Cellulose, 2011, 18, 1599-1609.

10 A. Hambardzumyan, L. Foulon, N. B. Bercu, M. Pernes, J. E. Maigret, M. Molinari, B. Chabbert and V. AguiéBéghin, Chem. Eng. J., 2015, 264, 780-788.

11 T. Saito, Y. Nishiyama, J. Putaux, A. Michel Vignon and A. Isogai, Biomacromolecules, 2006, 7, 1687-1691.

12 M. Shimizu, T. Saito, H. Fukuzumi and A. Isogai, Biomacromolecules, 2014, 15, 4320.

13 K. Xhanari, K. Syverud, G. Chinga-Carrasco, K. Paso and P. Stenius, Cellulose, 2011, 18, 257-270.

14 A. N. Nakagaito, Appl. Phys. A: Mater. Sci. Process., 2005, 80, 155-159. 
Paper

View Article Online

RSC Advances

15 F. Ansari, S. Galland, M. Johansson, C. J. G. Plummer and L. A. Berglund, Composites, Part A, 2014, 63, 35-44.

16 B. Guo, W. Chen and L. Yan, ACS Sustainable Chem. Eng., 2013, 1, 1474-1479.

17 M. S. Toivonen, S. Kurkisuonio, F. H. Schacher, S. Hietala, O. J. Rojas and O. Ikkala, Biomacromolecules, 2015, 16, 1062-1071.

18 K. Prakobna, S. Galland and L. A. Berglund, Biomacromolecules, 2015, 16, 904-912.

19 T. Obokata and A. Isogai, Colloids Surf., A, 2007, 302, 525531.

20 W. Zhang, Y. Zhang, C. Lu and Y. Deng, J. Mater. Chem., 2012, 22, 11642-11650.

21 S. Sharma and Y. Deng, Ind. Eng. Chem. Res., 2016, 55, 11467-11474.

22 W. Yang, L. Jiao, D. Min, Z. Liu and H. Dai, RSC Adv., 2017, 7, 10463-10468.

23 F. Azzam, L. Heux, J. L. Putaux and B. Jean, Biomacromolecules, 2010, 11, 3652-3659.

24 T. Katsutoshi, K. Yuichi and M. Masayuki, EP, EP0953679, 2002.
25 H. Zhu, Z. Fang, C. Preston, Y. Li and L. Hu, Energy Environ. Sci., 2013, 7, 269-287.

26 P. Lu and Y. L. Hsieh, Carbohydr. Polym., 2010, 82, 329-336.

27 H. Bian, G. Li, L. Jiao, Z. Yu and H. Dai, BioResources, 2016, 11, 10483-10496.

28 Y. Geng, K. Li and J. Simonsen, J. Appl. Polym. Sci., 2006, 99, 712-718.

29 Q. Yan, R. Sabo, Y. Wu, J. Y. Zhu and Z. Cai, Cellulose, 2015, 22, 1091-1102.

30 N. Pahimanolis, A. Salminen, P. A. Penttilä, J. T. Korhonen, L. S. Johansson, J. Ruokolainen, R. Serimaa and J. Seppälä, Cellulose, 2013, 20, 1459-1468.

31 M. Hakalahti, A. Salminen, J. Seppälä, T. Tammelin and T. Hänninen, Carbohydr. Polym., 2015, 126, 78-82.

32 M. Shimizu, T. Saito and A. Isogai, J. Membr. Sci., 2016, 500, $1-7$.

33 Y. Li, H. Zhu, M. Xu, Z. Zhuang, M. Xu and H. Dai, BioResources, 2014, 9, 1986-1997.

34 F. Jiang and Y. L. Hsieh, Carbohydr. Polym., 2013, 95, 32-40.

35 X. Sun, Q. Wu, S. Ren and T. Lei, Cellulose, 2015, 22, 11231133.

This journal is @ The Royal Society of Chemistry 2017

RSC Adv., 2017, 7, 31567-31573 | 31573 